\title{
Lauraceae no Morro dos Perdidos (Floresta Atlântica), Paraná, Brasil
}

\author{
Marcelo Leandro Brotto ${ }^{1}$, Élide Pereira dos Santos $^{2,4}$ \& João Batista Baitello ${ }^{3}$
}

\begin{abstract}
Resumo
(Lauraceae no Morro dos Perdidos (Floresta Atlântica), Paraná, Brasil) O Morro dos Perdidos está localizado

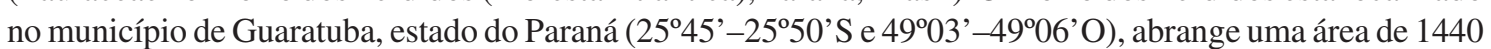
hectares de Floresta Ombrófila Densa, com altitudes entre 767 a 1439 m. Na área, a família Lauraceae está representada por 15 espécies: Cinnamomum hatschbachii; Cryptocarya aschersoniana; Endlicheria paniculata; Nectandra puberula; Ocotea bicolor; O. catharinensis; O. elegans; O. nunesiana; O. odorifera; O. porosa; O. pulchella; O. tristis; O. vaccinioides; Ocotea sp e Persea willdenovii. São apresentados chave, descrições, ilustrações e comentários sobre as espécies.
\end{abstract}

Palavras-chave: flora, neotrópicos, taxonomia, Serra do Mar.

\section{Abstract}

(Lauraceae in the Morro dos Perdidos (Atlantic Forest), Paraná State, Brazil) Morro dos Perdidos is located in Guaratuba, Paraná State ( $25^{\circ} 45^{\prime}-25^{\circ} 50^{\prime} \mathrm{S}$ and $\left.49^{\circ} 03^{\prime}-49^{\circ} 06^{\prime} \mathrm{W}\right)$, comprising 1440 hectares of Atlantic Rain Forest, with altitudes between 767 and $1439 \mathrm{~m}$. In the area, the family Lauraceae is represented by 15 species: Cinnamomum hatschbachii; Cryptocarya aschersoniana; Endlicheria paniculata; Nectandra puberula; Ocotea bicolor; O. catharinensis; O. elegans; O. nunesiana; O. odorifera; O. porosa; O. pulchella; $O$. tristis; O. vaccinioides; Ocotea sp and Persea willdenovii. Key, descriptions, illustrations and comments about the species are presented.

Key words: flora, neotropics, taxonomy, Serra do Mar.

\section{INTRODUÇÃo}

O Morro dos Perdidos é uma área de proteção ambiental bem preservada, no domínio da Floresta Ombrófila Densa (FOD). Está localizado na Serra de Araçatuba, município de Guaratuba, estado do Paraná $\left(25^{\circ} 45^{\prime}-25^{\circ} 50^{\prime} \mathrm{S}\right.$ e $\left.49^{\circ} 03^{\prime}-49^{\circ} 06^{\prime} \mathrm{O}\right)$, possui uma área de 1440 hectares recoberta por FOD Montana e Altomontana e por Refúgio Vegetacional Altomontano (campo graminoso de altitude), com altitudes entre 767 e $1439 \mathrm{~m}$.

Lauraceae é constituída por aproximadamente 50 gêneros, e 2500 a 3000 espécies distribuídas nas regiões tropicais e subtropicais do planeta (Werff \& Richter 1996), bem representada na América, Ásia tropical, Austrália e Madagascar e pouco expressiva no Sul da África (Rohwer 1986). Na região Neotropical Lauraceae está entre as famílias mais importantes, contribuindo para a riqueza de espécies em diferentes comunidades, especialmente nas florestas de terras baixas e em altitudes intermediárias, ou sobre solos pobres (Gentry 1988). No Brasil ocorrem 22 gêneros e cerca de 400 espécies (Lorenzi \& Souza 2008).

Algumas espécies de Lauraceae fornecem madeira de excelente qualidade, outras são utilizadas na culinária, na medicina popular, na fabricação de papel e em indústrias química e farmacêutica (Klein et al. 1979; Inoue et al. 1984; Marques 2001).

Artigo recebido em 11/2008. Aceito para publicação em 01/2009.

${ }^{1}$ Universidade Federal do Paraná, Bolsista Iniciação Científica Fundação Araucária.

${ }^{2}$ Universidade Federal do Paraná, Setor de Ciências Biológicas, Departamento de Botânica, Caixa Postal 19031, 81531970, Curitiba, PR, Brasil. Bolsista Produtividade em Pesquisa, CNPq.

${ }^{3}$ Instituto Florestal, Rua do Horto 931, 02377-000 Bairro Horto Florestal, São Paulo, SP, Brasil.

${ }^{4}$ Autor para correspondência: elide@ufpr.br 
A pressão extrativista sobre espécies madeiráveis resultou na diminuição de populações de Lauraceae, e as espécies Ocotea catharinensis Mez, O. odorifera (Vell.) Rohwer e O. porosa (Nees) Barroso, que ocorrem no Paraná, estão incluídas na lista oficial das espécies da flora brasileira ameaçadas de extinção (MMA 2008).

Em estudos fitossociológicos realizados na Floresta Ombrófila Densa no estado do Paraná, a família Lauraceae é citada entre as cinco mais representativas nas formações Montana e Altomontana e algumas de suas espécies são dominantes no estrato arbóreo (Rocha 1999; Roderjan et al. 2001; Blum 2006).

Trabalhos taxonômicos referentes às Lauraceae no estado do Paraná foram realizados por Vattimo (1956a, 1956b, 1962, 1979).

Lauraceae tem a reputação de ser uma família de difícil identificação, pois as flores são inconspícuas e os caracteres diagnósticos se referem às estruturas florais, como o número de estames, de esporângios na antera, condição sexual das flores e tépalas iguais ou desiguais (Werff 1991). Agrega-se também o fato de que muitas espécies são dióicas e as coleções nos acervos dos herbários são escassas, incompletas e com determinações incorretas.

Este estudo tem como objetivos apresentar o tratamento taxonômico da família Lauraceae no Morro dos Perdidos e ampliar o conhecimento sobre a diversidade desta família na Floresta Ombrófila Densa no estado do Paraná.

A publicação da "Flórula do Morro dos Perdidos" foi iniciada em 2000 e foram tratadas as famílias: Passifloraceae (Cervi \& Santos 2000); Plantaginaceae (Hefler et al. 2003), Clusiaceae (Slusarski et al. 2003), Iridaceae (Vieira et al. 2003), Ochnaceae (Salvador et al. 2005), Aquifoliaceae (Brotto et al. 2007) e Ericaceae (Silva et al. 2007).

\section{Material e Métodos \\ Área de estudo}

Foram realizadas expedições entre 1999 a 2008 para coleta de material botânico. As coletas foram incorporadas no acervo do herbário UPCB. As coleções depositadas nos herbários EFC, MBM, MO, NY, RB, SPSF e UPCB (siglas de acordo com Holmgren \& Holmgren 1998) foram analisadas. A identificação dos táxons foi estabelecida por meio de chaves de identificação, com base principalmente nos trabalhos de Quinet \& Andreata (2002) e Baitello (2003), com comparações de materiais depositados nos herbários e com descrições existentes em literatura especializada. Para as descrições foram utilizadas preferencialmente as coletas na área em estudo, e utilizou-se material adicional quando necessário para um melhor entendimento das espécies e para algumas ilustrações. A terminologia adotada baseou-se em Quinet \& Andreata (2002) e Baitello (2003). As ilustrações foram realizadas pelo primeiro autor. Para a abreviação dos nomes dos autores das espécies utilizou-se Brummit \& Powell (1992). A distribuição geográfica foi retirada das informações encontradas na literatura e ampliada com as consultas aos herbários.

\section{Resultados e Discussão}

As espécies de Lauraceae compreendem árvores ou arbustos monóicos, dióicos, ginodióicos e/ou polígamos, raro trepadeiras parasitas, em geral aromáticas, comumente perenifólias; folhas simples, alternas, subopostas ou subverticiladas, raro opostas, peninervadas, sub-3-plinervadas ou 3plinervadas, lâmina glabra ou pilosa, domácias presentes ou não; inflorescência axilar, raramente terminal, tirsóide, tirsóidepaniculada, racemiforme, pseudo-umbelada, raramente capitulada; flores em geral pequenas, unissexuadas ou bissexuadas, actinomorfas, tépalas 6 ou 4 em dois verticilos, raro 9 , iguais a desiguais, estames em 4 séries (I, II, III e IV), a série IV estaminoidal ou ausente, a série III com duas glândulas na base dos filetes, raro glândulas nas demais séries, filetes presentes ou ausentes, anteras 2-4 esporangiadas, esporângios deiscentes por valvas introrsas a extrorsas, quando díclinas 
as flores estaminadas apresentam pistilóide reduzido ou ausente e as pistiladas estaminódios, ovário súpero, unicarpelar, unilocular; fruto bacáceo, cúpula envolvendo o fruto parcialmente a totalmente, ou ausente (Quinet \& Andreata 2002; Baitello 2003).

Lauraceae está representada no Morro dos Perdidos por quinze espécies distribuídas em seis gêneros: Cinnamomum hatschbachii VattimoGil; Cryptocarya aschersoniana Mez; Endlicheria paniculata (Spreng.) J.F.Macbr.;
Nectandra puberula (Schott) Nees; Ocotea bicolor Vattimo-Gil; $O$. catharinensis Mez; $O$. elegans Mez; O. nunesiana (Vattimo-Gil) Baitello; O. odorifera (Vell.) Rohwer; O. porosa (Nees) Barroso; O. pulchella (Nees) Mez; $O$. tristis (Nees) Mez; O. vaccinioides (Meisn.) Mez; Ocotea sp. e Persea willdenovii Kosterm.

Ocotea elegans é citada pela primeira vez para o estado do Paraná enquanto que Persea willdenovii é registrada pela primeira vez na Floresta Ombrófila Densa Altomontana.

\section{Chave para as espécies de Lauraceae que ocorrem no Morro dos Perdidos}

1. Anteras 2-esporangiadas.

2. Folhas glabras, com 6-10 pares de nervuras laterais; flores bissexuadas; fruto totalmente incluso no hipanto acrescente (cúpula).

2. Cryptocarya aschersoniana

2'. Folhas pubescentes, com 3-6 pares de nervuras laterais; flores unissexuadas; fruto parcialmente envolvido pela cúpula

3. Endlicheria paniculata

1'. Anteras 4-esporangiadas.

3. Flores com esporângios das anteras das séries I e II dispostos em arco; folhas peninervadas com nervura central da face adaxial imersa e domácias nas axilas das nervuras laterais

4. Nectandra puberula

3'. Flores com esporângios das anteras das séries I e II dispostos em 2 pares sobrepostos; folhas peninervadas com nervura central da face adaxial imersa e sem domácias nas axilas das nervuras laterais, ou folhas peninervadas com nervura central da face adaxial saliente, subsaliente, plana, 3-plinervadas ou sub-3-plinervadas.

4. Flores com tépalas fortemente desiguais; folhas com ápice obtuso ou arredondado ...

15. Persea willdenovii

4'. Flores com tépalas iguais ou subiguais; folhas com ápice agudo, acuminado ou caudado.

5. Folhas 3-plinervadas até $5 \mathrm{~cm}$ compr.; flores com estaminódios cordiformes ...

1. Cinnamomum hatschbachii

5'. Folhas 3-plinervadas maiores que $5 \mathrm{~cm}$ de compr, ou sub-3-plinervadas ou peninervadas; flores com estaminódios não cordiformes ou ausentes.

6. Flores unissexuadas.

7. Folhas com domácias ausentes.

8. Folhas com 6-10 pares de nervuras laterais, reticulação laxa a subdensa; inflorescência glabra; fruto com cúpula de margem hexalobada 5. Ocotea bicolor

8'. Folhas com 4-6 pares de nervuras laterais, reticulação densa; inflorescência vilosa; fruto com cúpula de margem inteira ...

7'. Folhas com domácias presentes.

14. Ocotea sp.

9. Domácias distribuídas por toda a lâmina, não cobertas por tricomas

13. Ocotea vaccinioides

9'. Domácias presentes apenas nas axilas das nervuras laterais.

10. Folhas sub-3-plinervadas, face adaxial com reticulação densa; fruto elíptico, ca. $10 \mathrm{~mm}$ compr. 11. Ocotea pulchella 
10'. Folhas peninervadas, face adaxial com reticulação laxa; fruto globoso, ca. $7 \mathrm{~mm}$ compr. 12. Ocotea tristis

6'. Flores bissexuadas.

11. Folhas com domácias ausentes.

12. Flores pubescentes; fruto com cúpula infundibuliforme; folhas com pecíolo de 12-25 mm compr., não canaliculado 8. Ocotea nunesiana

12'. Flores glabras; fruto com cúpula hemisférica; folhas com pecíolo de 10-15 mm compr., canaliculado 9. Ocotea odorifera

11'. Folhas com domácias presentes.

13. Domácias distribuídas por toda a lâmina, não cobertas por tricomas; inflorescência paniculada; flores com estaminódios ausentes 13. Ocotea vaccinioides

13'. Domácias quando presentes, apenas nas axilas das nervuras laterais, cobertas por tricomas; inflorescência racemosa; flores com estaminódios.

14. Fruto globoso com cúpula subemisférica a quase plana

10. Ocotea porosa

14'. Fruto elipsóide com cúpula hemisférica.

15. Folhas 3-plinervadas, sub-3-plinervadas, raro peninervadas; flores com filetes dos estames das séries I e II iguais ou maiores que as anteras

6. Ocotea catharinensis

15'. Folhas peninervadas; flores com filetes dos estames das séries I e II com $1 / 4$ do comprimento das anteras

7. Ocotea elegans

1. Cinnamomum hatschbachii Vattimo-Gil, Arq. Jard. Bot. Rio de Janeiro 17: 222. 1962.

Fig. 1 (a1-a6)

Árvore monóica, até $6,5 \mathrm{~m}$ alt. Folhas alternas, 3-plinervadas, lâmina 2-5 $\times 1,5-3 \mathrm{~cm}$, elíptica, ápice agudo ou obtuso, base aguda, raro obtusa, face adaxial glabra, reticulação densa, inconspícua, nervura central imersa, nervuras laterais planas, face abaxial glabrescente, reticulação densa, conspícua, nervuras salientes, domácias nas axilas das nervuras, cobertas por tricomas alvos, pecíolo 5-10 mm compr., canaliculado, glabro. Inflorescência ca. $3 \mathrm{~cm}$ compr., no ápice dos ramos, racemosa, pauciflora, pubescente. Flores bissexuadas, ca. $3 \mathrm{~mm}$ diâm., pubescentes, tépalas ca. 1,6 mm compr., iguais, ovaladas, anteras 4esporangiadas, esporângios dispostos em 2 pares sobrepostos, estames das séries I e II ca. $1 \mathrm{~mm}$ compr., anteras ovaladas, filetes com $1 / 2$ do comprimento das anteras, pubescentes, estames da série III ca. 1,2 mm compr., anteras ovaladoretangulares, filetes pubescentes, estaminódios cordiformes, pubescentes, pistilo ca. $1,8 \mathrm{~mm}$ compr., glabro, ovário subgloboso, estilete longo. Fruto ca. $9 \times 7 \mathrm{~mm}$, elipsóide, cúpula ca. $9 \times 5$ $\mathrm{mm}$, obcônica, margem inteira.
Material examinado: BRASIL. PARANÁ: Guaratuba, Serra de Araçatuba, 31.I.1960, fl., G. Hatschbach 6682 (Holotypus: RB, Isotypus: MBM, MO, NY); 21.I.1994, fl., $R$. Kummrow et al. 3354 (MBM); 23.IV.1999, fr., E.P. Santos et al. 779 (UPCB); 30.III.2001, fl., E.P. Santos \& L.G. Socher 874 (UPCB); 25.I.2007, fl., M.L. Brotto et al. 6 (SPSF, UPCB); 30.III.2007; fr., M.L. Brotto \& E.P. Santos 15 (SPSF, UPCB).

Ocorre no Paraná e em Santa Catarina na FOD. No Morro dos Perdidos é encontrada no patamar Altomontano a partir de $1200 \mathrm{~m}$ s.n.m. Por falta de dados sobre sua distribuição foi incluída na lista oficial de espécies ameaçadas de extinção da flora brasileira com deficiência de dados publicada pelo MMA (2008). A análise das coleções mostrou que a espécie tem distribuição restrita à Serra do Mar, entre o Paraná e Santa Catarina. Os caracteres florais se assemelham ao das espécies do gênero Ocotea, a principal diferença se refere às folhas que são 3 plinervadas até $5 \mathrm{~cm}$ compr., enquanto que em Ocotea são 3-plinervadas maior que $5 \mathrm{~cm}$ compr., sub-3-plinervadas ou peninervadas. Em material vivo a cúpula do fruto é avermelhada. Coletada com flores de janeiro a março e com frutos de março a abril. 


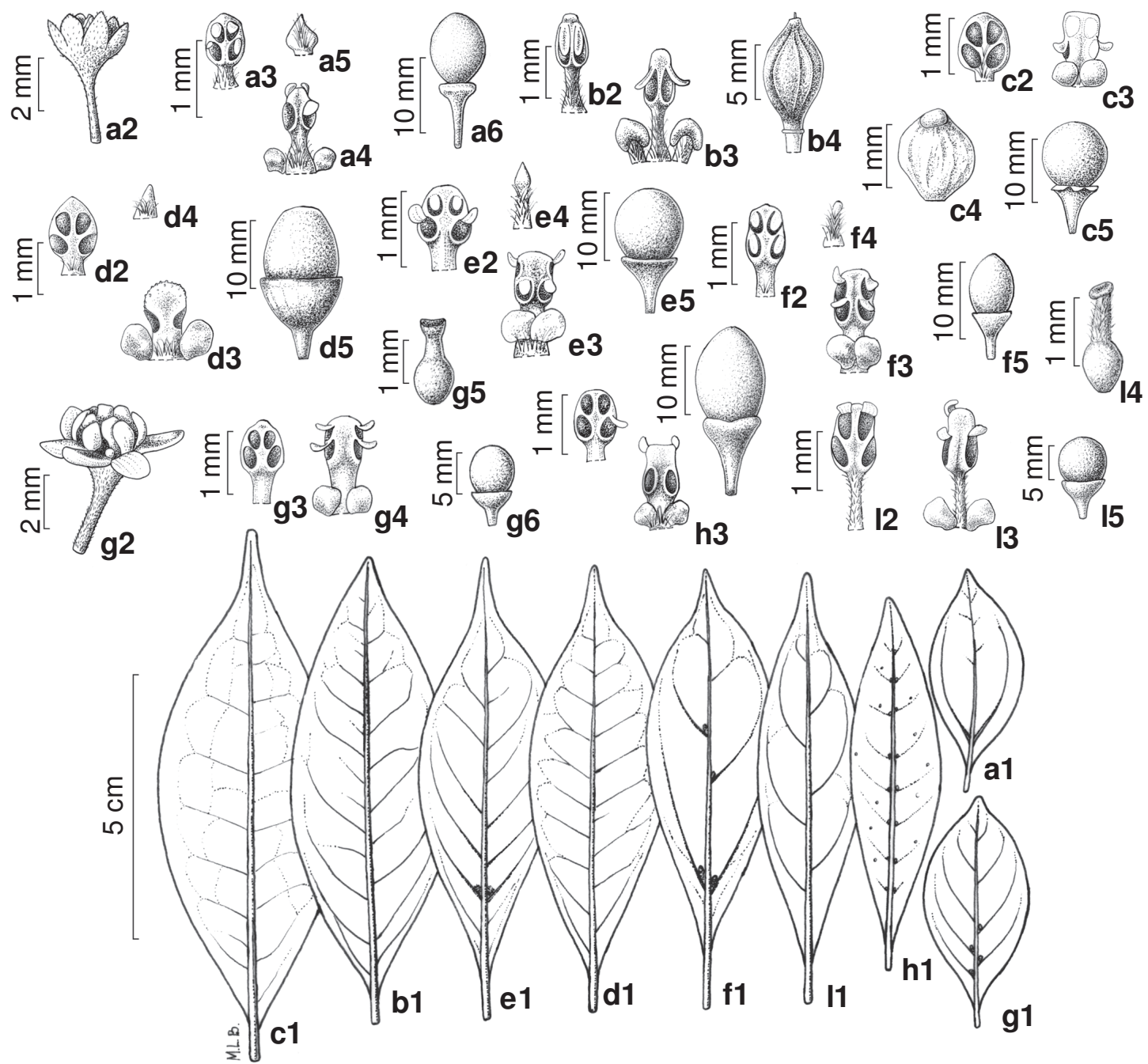

Figura 1 - a. Cinnamomum hatschbachii Vattimo-Gil - a1. folha; a2. flor; a3. estame da série I; a4. estame da série III; a5. estaminódio da série IV; a6. fruto. b. Cryptocarya aschersoniana Mez-b1. folha; b2. estame da série I; b3. estame da série III; b4. fruto. c. Ocotea bicolor Vattimo-Gil - c1. folha; c2. estame da série I; c3. estame da série III; c4. pistilo; c5. fruto. d. Ocotea elegans $\mathrm{Mez}$ - d1. folha; d2. estame da série I; d3. estame da série III; d4. estaminódio da série IV; d5. fruto. e. Ocotea porosa (Nees) Barroso - e1. folha; e2. estame da série I; e3. estame da série III; e4. estaminódio da série IV; e5. fruto. f. Ocotea pulchella (Nees) Mez -f1. folha; f2. estame da série I; f3. estame da série III; f4. estaminódio da série IV; f5. fruto. g. Ocotea tristis (Nees) Mez - g1. folha; g2. flor; g3. estame da série I; g4. estame da série III; g5. pistilo; g6. fruto. h. Ocotea vaccinioides (Meisn.) Mez - h1. folha; h2. estame da série I; h3. estame da série III; h4. fruto. I. Ocotea sp. - i1. folha; i2. estame da série I; i3. estame da série III; i4. pistilo; i5. fruto. (a1-a5 Santos 874; a6 Brotto 15; c1 Brotto 41; c2-c3 Reginato 658; c4 Reginato 205; c5 Ribas 2133; d1,d5 Brotto 11; d2-d4 Svolenski 303; e1-e4 Brotto 9; e5 Brotto 3; f1-f4 Santos 873; f5 Santos 1070; g1-g4 Brotto 17; g5 Brotto 18; g6 Santos 732; h1-h3 Roderjan 1139; h4 Brotto 5; i1,i4 Santos 1184; i2-i3 Silva 838; i5 Brotto 39).

Figure 1 - a. Cinnamomum hatschbachii Vattimo-Gil - a1. leaf; a2. flower; a3. stamen from serie I; a4. stamen from the serie III; a5. staminodium from the serie IV; a6. fruit. b. Cryptocarya aschersoniana Mez - b1. leaf; b2. stamen serie I; b3. stamen from the serie III; b4. fruit. c. Ocotea bicolor Vattimo-Gil - c1. leaf; c2. stamen from the serie I; c3. stamen from the serie III; c4. pistil; c5. fruit. d. Ocotea elegans Mez - d1. leaf; d2. stamen from the serie I; d3. stamen from the serie III; d4. staminodium from the serie IV; d5. fruit. e. Ocotea porosa (Nees) Barroso - e1. leaf; e2. stamen from the serie I; e3. stamen from the serie III; e4. staminodium from the serie IV; e5. fruit. f. Ocotea pulchella (Nees) Mez - f1. leaf; f2. stamen from the serie I; f3. stamen from the serie III; f4. staminodium from the serie IV; f5. fruit. g. Ocotea tristis (Nees) Mez - g1. leaf; g2. flower; g3. stamen from the serie I; g4. stamen from the serie III; g5. pistil; g6. fruit. h. Ocotea vaccinioides (Meisn.) Mez - h1. leaf; h2. stamen from the serie I; h3. stamen from the serie III; h4. fruit. i. Ocotea sp. - i1. leaf; i2. stamen from the serie I; i3. stamen from the serie III; i4. pistil; i5. fruit. (a1-a5 Santos 874; a6 Brotto 15; c1 Brotto 41; c2-c3 Reginato 658; c4 Reginato 205; c5 Ribas 2133; d1,d5 Brotto 11; d2-d4 Svolenski 303; e1-e4 Brotto 9; e5 Brotto 3; f1-f4 Santos 873; f5 Santos 1070; g1-g4 Brotto 17; g5 Brotto 18; g6 Santos 732; h1-h3 Roderjan 1139; h4 Brotto 5; i1,i4 Santos 1184; i2-i3 Silva 838; i5 Brotto 39). 
2. Cryptocarya aschersoniana Mez, Jahrb. Königl. Bot. Gart. Berlin 5: 11. 1889.

Fig. 1 (b1-b4)

Árvore monóica, até $15 \mathrm{~m}$ alt. Folhas alternas, peninervadas, lâmina 5,5-14×2-5 cm, elíptica, ápice agudo, base aguda, glabra, reticulação densa, conspícua, face adaxial com nervura central subsaliente, as laterais planas, face abaxial com nervura central saliente, nervuras laterais subsalientes, 6-10 pares, domácias ausentes, pecíolo 6-12 mm compr., subcanaliculado, glabro. Inflorescência ca. $3 \mathrm{~cm}$, no ápice dos ramos e axilar, paniculada, multiflora, pubérula, bractéolas persistentes. Flores bissexuadas, ca. 4 mm diâm., glabrescentes, tépalas ca. 2,3 mm compr., iguais, ovaladas, anteras 2-esporangiadas, estames das séries I e II ca. 2 mm compr., anteras ovalado-triangulares, filetes com o mesmo comprimento que as anteras, pubescentes, estames da série III ca. 2,2 mm compr., anteras ovalado-triangulares, filetes pubescentes, estaminódios sagitados, pubescentes, pistilo ca. $2 \mathrm{~mm}$ compr., fino, pubescente. Fruto elipsóidegloboso, ca. $10 \times 5 \mathrm{~mm}$, costulado ou com vestígios de costulações, totalmente incluso no hipanto acrescente (cúpula).

Material examinado: BRASIL. PARANÁ: Guaratuba, Boa Vista, 25.X.1984, fl., G. Hatschbach 48552 (UPCB); Serra de Araçatuba, 10.X.2001, fl., E.P. Santos \& C. Blum 1056 (UPCB); 18.XII.2001, fr., E.P. Santos et al. 1098 (SPSF, UPCB).

Ocorre no Distrito Federal, Sudeste e Sul do Brasil, desde o Espírito Santo até Rio Grande do Sul, na Floresta Estacional Semidecidual (FES), Floresta Ombrófila Mista (FOM) e FOD. No Morro dos Perdidos é frequente no patamar Montano a $850 \mathrm{~m}$ s.n.m. Caracteriza-se pelo fruto totalmente incluso no hipanto acrescente (cúpula). Coletada com flores em outubro e com frutos em dezembro.

\section{Endlicheria paniculata (Spreng.)} J.F.Macbr., Publ. Field Mus. Nat. Hist., Bot. Ser. 13(2): 850. 1938.

Fig. 2 (a1-a4)

Árvore dióica, até $5 \mathrm{~m}$ alt. Folhas alternas, peninervadas, lâmina 8,5-27×3,5-8 cm, elíptica, ápice acuminado ou caudado, base aguda, reticulação laxa, conspícua, face adaxial glabrescente, velutina sobre as nervuras, nervuras central e laterais planas, face abaxial pubescente, velutina sobre as nervuras, nervuras central e laterais salientes, 3-6 pares, domácias ausentes, pecíolo 10-25 mm compr., não canaliculado, velutino. Inflorescência ca. $7 \mathrm{~cm}$ compr., axilar, paniculada, multiflora, velutina. Flores unissexuadas; estaminadas, ca. 5 mm diâm., pubescentes, tépalas ca. 2,8 $\mathrm{mm}$ compr., iguais, estreito elípticas, anteras 2-esporangiadas, estames das séries I e II ca. $1 \mathrm{~mm}$ compr., anteras orbiculares, filetes com o mesmo comprimento que as anteras, pubérulos, estames da série III ca. $1 \mathrm{~mm}$ compr., anteras ovaladotriangulares, filetes pubérulos, estaminódios ausentes, pistilóide diminuto; pistiladas ca. $3 \mathrm{~mm}$ de diâm., pubérulas, tépalas ca. $1,5 \mathrm{~mm}$, ovaladoelípticas, estaminódios ca. 0,8 mm compr., pistilo ca. 1,7 mm compr., glabro, ovário globoso, estilete muito curto. Fruto ca. $18 \times 10 \mathrm{~mm}$, elíptico, parcialmente envolvido pela cúpula ca. $8 \times 6 \mathrm{~mm}$, subemisférica, rasa, margem inteira.

Material examinado: BRASIL. PARANÁ: Antonina, Serra Negra, 23.XI.1966, fl. $\uparrow, G$. Hatschbach 14123 (UPCB); Guaratuba, Serra de Araçatuba, 10.III.1996, fl. Oे, O.S. Ribas \& L.B.S. Pereira 1374 (MBM), 28.IX.2001, fr., E.P. Santos \& A.C. Cervi 1045 (UPCB); 18.XII.2001, fl. đै, E.P. Santos et al. 1092 (SPSF, UPCB).

Ocorre na América tropical e em todo o Brasil, na FES, FOD e no Cerrado. No Morro dos Perdidos é encontrada no patamar Montano a 850 m s.n.m. É a única espécie de Lauraceae na área com as nervuras das folhas velutinas. Coletada com flores de novembro a março e com frutos em setembro.

\section{Nectandra puberula (Schott) Nees, Syst.} Laur.: 332. 1836.

Fig. 2 (b1-b4)

Árvore monóica, até $7 \mathrm{~m}$ alt. Folhas alternas, peninervadas, lâmina 4,5-14×1,5-3 $\mathrm{cm}$, lanceolada, ápice acuminado, base aguda, reticulação subdensa, conspícua, face adaxial glabra, nervura central imersa, nervuras laterais planas, face abaxial pubérula, nervuras central e laterais salientes, 5-8 pares, domácias nas axilas das nervuras, cobertas por tricomas amarelo-ferrugíneos, pecíolo 5-15 mm compr., 


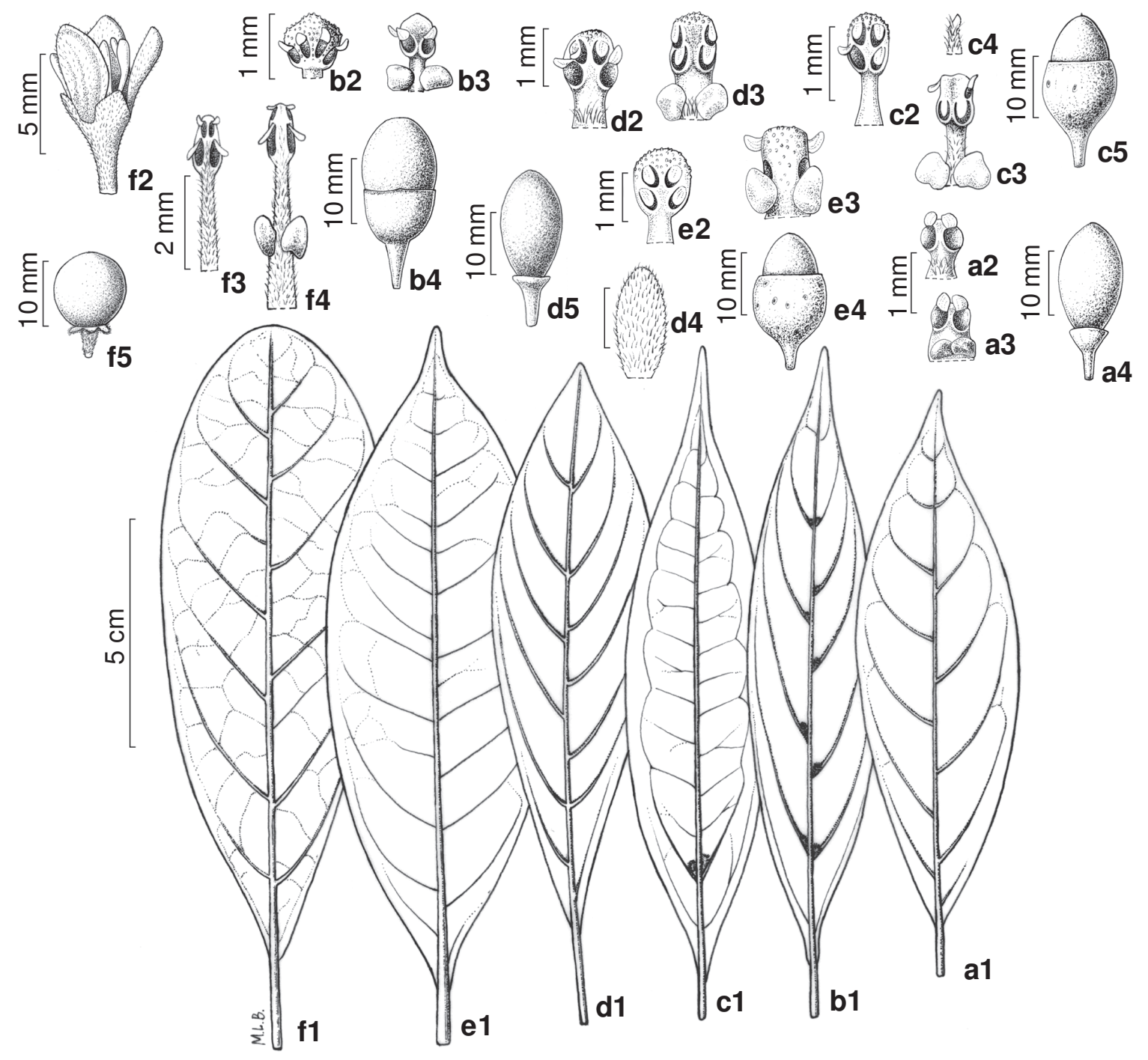

Figura 2 - a. Endlicheria paniculata (Spreng.) J.F.Macbr. - a1. folha; a2. estame da série I; a3. estame da série III; a4. fruto. b. Nectandra puberula (Schott) Nees - b1. folha; b2. estame da série I; b3. estame da série III; b4. fruto. c. Ocotea catharinensis Mez - c1. folha; c2. estame da série I; c3. estame da série III; c4. estaminódio da série IV; c5. fruto. d. Ocotea nunesiana (Vattimo-Gil) Baitello - d1. folha; d2. estame da série I; d3. estame da série III; d4. tépala; d5. fruto. e. Ocotea odorifera (Vell.) Rohwer - e1. folha; e2. estame da série I; e3. estame da série III; e4. fruto. f. Persea willdenovii Kosterm. - f1. folha; f2. flor; f3. estame da série I; f4. estame da série III; f5. fruto. (a1,a4 Santos 1045; a2-a3 Ribas 1374; b1,b4 Zanon 45; b1-b2 Ribas 1349; c1 Brotto 42; c2-c4 Kuniyoshi 4841; c5 Hatschbach 7426; d1-d4 Santos 1055; d5 Klein 3142; e1 Brotto 40; e2-e3 Reginato 672; e4 Negrelle 686; f1 Brotto 27; f2-f4 Muller s.n MBM 283048; f5 Ribas 1476).

Figura 2 - a. Endlicheria paniculata (Spreng.) J.F.Macbr. - a1. leaf; a2. stamen from the serie I; a3. stamen from the serie III; a4. fruit. b. Nectandra puberula (Schott) Nees - b1. folha; b2. stamen from the serie I; b3. stamen from the serie III; b4. fruit. c. Ocotea catharinensis $\mathrm{Mez}-\mathrm{c} 1$. leaf; c2. stamen from the serie I; c3. stamen from the serie III; c4. staminodium from the serie IV; c5. fruit. d. Ocotea nunesiana (Vattimo-Gil) Baitello - d1. leaf; d2. stamen from the serie I; d3. stamen from the serie III; d4. tepal; d5. fruit. e. Ocotea odorifera (Vell.) Rohwer - e1. leaf; e2. stamen from the serie I; e3. stamen from the serie III; e4. fruit. f. Persea willdenovii Kosterm. - f1. leaf; f2. flower; f3. stamen from the serie I; f4. stamen from the serie III; f5. fruit. (a1,a4 Santos 1045; a2-a3 Ribas 1374; b1,b4 Zanon 45; b1-b2 Ribas 1349; c1 Brotto 42; c2-c4 Kuniyoshi 4841; c5 Hatschbach 7426; d1-d4 Santos 1055; d5 Klein 3142; e1 Brotto 40; e2-e3 Reginato 672; e4 Negrelle 686; f1 Brotto 27; f2-f4 Muller s.n MBM 283048; f5 Ribas 1476). 
subcanaliculado, glabrescente. Inflorescência ca. $10 \mathrm{~cm}$ compr., subterminal e axilar, paniculada, multiflora, pubérula. Flores bissexuadas, ca. $6 \mathrm{~mm}$ diâm., pubérulas, tépalas ca. $3 \mathrm{~mm}$ compr., iguais, elípticas, papilosas, anteras 4-esporangiadas, estames das séries I e II ca. $1 \mathrm{~mm}$ compr., anteras orbicularpentagonais, papilosas, até $1 / 4$ mais largas que longas, esporângios dispostos em arco, filetes com $1 / 4$ do comprimento das anteras, glabros, estames da série III ca. 1,3 mm compr., anteras retangulares, esporângios em dois pares sobrepostos, filetes glabros, estaminódios sagitados, glabros, pistilo ca. $2 \mathrm{~mm}$ compr., glabro, ovário globoso, estilete curto. Fruto ca. $14 \times 12 \mathrm{~mm}$, elipsóide, cúpula ca. $17 \times 11 \mathrm{~mm}$, trompetiforme, margem inteira.

Material examinado: BRASIL. PARANÁ: Guaratuba, Serra de Araçatuba, 10.III.1996, fl., O.S. Ribas \& L.B.S. Pereira 1349 (MBM); 31.X.2006, fr., M.M.F. Zanon \& M.L. Brotto 45 (SPSF, UPCB). SANTA CATARINA: Campo Alegre, Serra do Quiriri, 03.III.2001, fl., O.S. Ribas et. al. 3325 (MBM).

Ocorre nas Regiões Nordeste, CentroOeste, Sudeste e Sul do Brasil, na FOM e FOD. No Morro dos Perdidos é encontrada no patamar Montano a $850 \mathrm{~m}$ s.n.m. Das espécies de Lauraceae que ocorrem no Morro dos Perdidos é a única com esporângios dos estames das séries I e II dispostos em arco. Coletada com flores em março e frutos em outubro.

\section{Ocotea bicolor Vattimo-Gil, Rodriguésia 18 -} 19(30-31): 302. $1956 . \quad$ Fig. 1 (c1-c5)

Árvore dióica, até $21 \mathrm{~m}$ alt. Folhas alternas, peninervadas, lâmina 5-10×1-3,5 cm, elíptica a lanceolada, ápice agudo ou caudado, base aguda, glabra, reticulação laxa a subdensa, conspícua, face adaxial com nervuras central e laterais planas, face abaxial com nervura central saliente, nervuras laterais subsalientes, 6-10 pares, domácias ausentes, pecíolo 5-10 mm compr., canaliculado, glabro. Inflorescência ca. $7 \mathrm{~cm}$ compr., subterminal, paniculada, multiflora, glabra. Flores unissexuadas; estaminadas ca. 3 mm diâm., glabras, tépalas ca. 1,8 mm compr., subiguais, ovaladas, anteras 4-esporangiadas, esporângios dispostos em 2 pares sobrepostos, estames das séries I e II ca. 1,3 mm compr., anteras ovaladas, filetes $\operatorname{com} 1 / 3$ do comprimento das anteras, glabrescentes, estames da série III ca. $1,5 \mathrm{~mm}$, anteras retangulares, filetes glabrescentes, estaminódios e pistilóide ausentes; pistiladas ca. $3 \mathrm{~mm}$ diâm., glabras, tépalas ca. 1,3 mm compr., subiguais, ovaladas, estaminódios ca. 0,6 mm compr., pistilo ca. 1,2 mm compr., glabro, ovário globoso, estilete curtíssimo. Fruto ca. $15 \times 13 \mathrm{~mm}$, globosoelíptico, cúpula ca. $8 \times 7 \mathrm{~mm}$, trompetiforme, rasa, margem hexalobada.

Material examinado: BRASIL. PARANÁ: Guaratuba, Serra de Araçatuba, 25.IX.2007, est., M.L. Brotto et al. 41 (UPCB); 17.VI.2008, fr., M.L. Brotto \& F. Marinero 152 (UPCB); Piraquara, Mananciais da Serra, I.2005, fl. ${ }^{7}$, M. Reginato 156 (UPCB); II.2005, fl. o, M. Reginato 205 (UPCB); I.2006, fl. đ̂, M. Reginato 658 (UPCB); São José dos Pinhais, 20.XII.2007, fl. Oै, M.L. Brotto 46 (SPSF, UPCB); Tijucas do Sul, Serra da Papanduva, 15.XII.1997, fr., O.S. Ribas et al. 2133 (MBM).

Ocorre no Paraná e na Região Sudeste do Brasil, na FOM, FOD e no Cerrado. No Morro dos Perdidos é freqüente no patamar Montano a $850 \mathrm{~m}$ s.n.m. Suas folhas, quando desidratadas, adquirem duas tonalidades e a nervura central torna-se avermelhada. Coletada com frutos em junho.

Ocotea bicolor é frequentemente confundida com com $O$. corymbosa (Meiss.) Mez e $O$. acutifolia, porém estas espécies apresentam área de ocorrência e caracteres morfológicos distintos. O. bicolor é encontrada na Floresta Ombrófila Mista (FOM) e Densa, $O$. corymbosa na Floresta Estacional Semidecidual (FES). Em O. bicolor a inflorescência e as flores são glabras enquanto que em $O$. corymbosa elas são pilosas. O fruto em $O$. bicolor é globoso com cúpula de margem hexalobada e em $O$. acutifolia é elíptico com cúpula de margem inteira.

6. Ocotea catharinensis Mez, Bot. Jahrb. Syst. 30(67): 19. $1901 . \quad$ Fig. 2 (c1-c5)

Árvore monóica, até $17 \mathrm{~m}$ alt. Folhas alternas ou opostas no ápice dos râmulos, 3plinervadas, sub-3-plinervadas, raro 
peninervadas, lâmina $8-15 \times 2-4 \mathrm{~cm}$, lanceolada, ápice acuminado ou caudado, base aguda, glabra, reticulação densa, conspícua, face adaxial com nervura central subsaliente, nervuras laterais planas, buladas sobre as domácias, face abaxial com nervura central saliente, nervuras laterais subsalientes, 6-8 pares, domácias presentes apenas nas axilas das nervuras laterais basais, cobertas por tricomas alvos, pecíolo 5-10 mm compr., não canaliculado, glabro. Inflorescência ca. $4 \mathrm{~cm}$ compr., subterminal e axilar, racemosa, pauciflora, pubérula. Flores bissexuadas, ca. 4 $\mathrm{mm}$ diâm., pubérulas, tépalas ca. 1,6 mm compr., subiguais, elípticas, anteras 4esporangiadas, esporângios dispostos em 2 pares sobrepostos, estames das séries I e II ca. 1,7 mm compr., anteras elípticoretangulares, filetes iguais ou maiores que as anteras, glabrescentes, estames da série III ca. 1,8 mm compr., anteras retangulares, filetes pubérulos, estaminódios filiformes, pubérulos, pistilo ca. 2,5 mm compr., glabro, ovário estreito-elíptico, estilete longo. Fruto ca. $12 \times$ $10 \mathrm{~mm}$, elípsóide, cúpula ca. $18 \times 12 \mathrm{~mm}$, hemisférica, lenticelada, margem inteira.

Material examinado: BRASIL. PARANÁ: Campina Grande do Sul, Jaguatirica, 13.XI.1960, fr., $G$. Hatschbach 7426 (MBM); Guaraqueçaba, faz. Madezatti, 22.II.1985, fl., Y.S. Kuniyoshi 4841 (EFC); Guaratuba, Serra de Araçatuba, 25.IX.2007, est., M.L. Brotto et al. 42 (UPCB).

Ocorre nas Regiões Sudeste e Sul do Brasil, na FES e FOD. No Morro dos Perdidos é freqüente no patamar Montano a $850 \mathrm{~m}$ s.n.m. Espécie incluída na lista oficial das espécies da flora brasileira ameaçadas de extinção (MMA 2008). Apresenta fruto semelhante ao de $O$. elegans, mas difere desta pela nervação da folha, forma das anteras e dos filetes dos estames.

7. Ocotea elegans Mez, Jahrb. Königl. Bot. Gart. Berlin 5: 385. $1889 . \quad$ Fig. 1 (d1-d5)

Árvore monóica, até $15 \mathrm{~m}$ alt. Folhas alternas, peninervadas, lâmina 4,5-10 × 1,5-3,5 $\mathrm{cm}$, elíptica, raro lanceolada, ápice acuminado ou caudado, base aguda, glabra, face adaxial com reticulação densa, inconspícua, nervura central subsaliente, nervuras laterais planas, face abaxial com reticulação densa, conspícua, nervura central saliente, nervuras laterais planas, 8-11 pares, ângulo de divergência das nervuras $60^{\circ}$, domácias raras, se presentes apenas nas axilas das nervuras laterais basais, cobertas por tricomas alvos, pecíolo 6-11 $\mathrm{mm}$ compr., canaliculado, glabro. Inflorescência ca. $4 \mathrm{~cm}$ compr., no ápice dos ramos, racemosa, pauciflora, pubescente. Flores bissexuadas, ca. 5 mm diâm., pubérulas, tépalas ca. $2 \mathrm{~mm}$ compr., subiguais, ovaladas, anteras 4-esporangiadas, esporângios dispostos em 2 pares sobrepostos, estames das séries I e II ca. 1,3 mm compr., anteras ovaladas, filetes com $1 / 4$ do comprimento das anteras, glabrescentes, estames da série III ca. 1,5 mm compr., anteras retangulares, filetes pubérulos, estaminódios subsagitados no ápice, pubérulos, pistilo glabro ca. 2,4 mm compr., ovário elíptico, estilete curto. Fruto ca. $17 \times 12$ $\mathrm{mm}$, elipsóide, cúpula ca. $13 \times 13 \mathrm{~mm}$, hemisférica, margem inteira.

Material examinado: BRASIL. PARANÁ: Campo Largo, Pinheirinho, 23.VI.1996, fl., A.C. Svolenski \& G. Tiepolo 303 (EFC, MBM); Guaratuba, Serra de Araçatuba, 25.VI.1968, fl., G. Hatschbach 19423 (MBM), 18.XII.2001, fr., E.P. Santos et al. 1102 (SPSF, UPCB); 25.I.2007, fr., M.L. Brotto et al. 11 (SPSF, UPCB).

Ocorre no Paraná e na Região Sudeste do Brasil, na FES e FOD. No Morro dos Perdidos é encontrada no patamar Montano a $850 \mathrm{~m}$ s.n.m. Assemelha-se a $O$. porosa diferindo pela forma do fruto e da cúpula e na folha pelo ângulo de divergência das nervuras, em $O$. elegans é de $60^{\circ}$ e em $O$. porosa é de $40^{\circ}$. Coletada com flores em junho com frutos de dezembro a janeiro.

8. Ocotea nunesiana (Vattimo-Gil) Baitello, Flora Fanerogâmica do Estado São Paulo 3: 198. 2003.

Fig. 2 (d1-d5)

Árvore monóica, até $16 \mathrm{~m}$ alt. Folhas alternas, peninervadas, lâmina 6-14×2-3,5 cm, elíptica a obovada, ápice agudo, base aguda, glabrescente, reticulação laxa, conspícua, face 
adaxial com nervuras central e laterais planas, face abaxial com nervuras central e laterais salientes, 6-9 pares, domácias ausentes, pecíolo 12-25 mm compr., não canaliculado, glabro. Inflorescência ca. $6 \mathrm{~cm}$ compr., subterminal, paniculada, pauciflora, pubescente. Flores bissexuadas, ca. $7 \mathrm{~mm}$ diâm., pubescentes, tépalas ca. 3,5 mm compr., iguais, estreito-elípticas, anteras 4esporangiadas, esporângios dispostos em 2 pares sobrepostos, estames das séries I e II ca. 1,6 mm compr., anteras ovaladoquadrangulares, papilosas, filetes com igual comprimento que as anteras, glabrescentes, estames da série III ca. 1,6 mm compr., anteras retangulares, filetes glabrescentes, estaminódios subsagitados no ápice, glabrescentes, pistilo ca. 2,3 mm compr., glabro, ovário globoso-elipsóide, estilete curto. Fruto ca. 17 x $10 \mathrm{~mm}$, elíptico, cúpula ca. 7 × $6 \mathrm{~mm}$, infundibuliforme, lenticelada, margem inteira. Material examinado: BRASIL. PARANÁ: Colombo, Embrapa, 13.X.1995, fl., W. Maschio 74 (MBM); Guaratuba, Serra de Araçatuba, 10.X.2001, fl. e fr., E.P. Santos et al. 1055 (SPSF, UPCB); Morretes, 29.IX.1986, fr., Y.S. Kuniyoshi 5016 (MBM); Paranaguá, 19.VI.1987, fr., Y.S. Kuniyoshi \& S.R. Ziller 5199 (MBM), São José dos Pinhais, Castelhanos, 25.VIII.2001, fr., A. Dunaiski Jr et al. 1714 (MBM). SANTA CATARINA: Garuva, 04.XII.1962, fl., R. Klein 3157 (MBM); Ibirama, 13.IV.1956, fr., R. Klein 3142 (MBM).

Ocorre no Rio de Janeiro, São Paulo, Paraná e Santa Catarina, na FOM e FOD. No Morro dos Perdidos é encontrada no patamar Montano a 850 m s.n.m. Das espécies de Lauraceae que ocorrem no Morro dos Perdidos é a única com tépalas com ca. 3,5 mm compr., iguais, estreito-elípticas, pubescentes. Difere das demais espécies de Ocotea pelo pecíolo longo, 12-25 mm compr. Coletada com flores e frutos em outubro.

9. Ocotea odorifera (Vell.) Rohwer, Mitt. Inst. Allg. Bot. Hamburg 20: 111. 1986.

Fig. 2 (e1-e4)

Árvore monóica, até $6 \mathrm{~m}$ alt. Folhas alternas para a base dos râmulos e subverticiladas para o ápice, peninervadas, lâmina $11,5 \times 3,5-5,5$ $\mathrm{cm}$, elíptica, ápice acuminado, base aguda, glabra, reticulação densa, conspícua, face adaxial nervura central plana a subsaliente, nervuras laterais planas, face abaxial com nervuras central e laterais subsalientes, 8-12 pares, domácias ausentes, pecíolo 10-15 mm compr., canaliculado, glabro. Inflorescência ca. $8 \mathrm{~cm}$ compr., agrupada ao redor da gema apical, paniculada, submultiflora, glabra. Flores bissexuadas, ca. $3 \mathrm{~mm}$ diâm., glabras, tépalas ca. $3 \mathrm{~mm}$, iguais, elípticas, anteras 4esporangiadas, esporângios dispostos em 2 pares sobrepostos, estames das séries I e II ca. $1,8 \mathrm{~mm}$ compr., anteras orbiculares, papilosas, filetes com igual comprimento que as anteras, glabros, estames da série III ca. $1,8 \mathrm{~mm}$ compr., anteras retangulares, papilosas, filetes glabros, estaminódios ausentes, pistilo ca. 2,4 mm compr., glabro, ovário elipsóide, estilete curto. Fruto ca. 20 x 10 mm, elipsóide, cúpula ca. 16 x $12 \mathrm{~mm}$, hemisférica, lenticelada, margem inteira.

Material examinado: BRASIL. PARANÁ: Piraquara, Mananciais da Serra, II.2006, fl., $M$. Reginato 672 (UPCB); Tijucas do Sul, Saltinho, 28.VI.1960, fr., G. Hatschbach 6998 (MBM, RB); Guaratuba, Serra de Araçatuba, 25.IX.2007, est., M.L. Brotto et al. 40 (UPCB). SANTA CATARINA: Itapoá, Reserva Volta Velha, 21.I.1993, fl. e fr., R.R.B. Negrelle 686 (UPCB).

Ocorre no sul da Bahia e nas Regiões Sudeste e Sul do Brasil, na FES, FOM e FOD. No Morro dos Perdidos é encontrada no patamar Montano a $850 \mathrm{~m}$ s.n.m. Espécie incluída na lista oficial das espécies da flora brasileira ameaçadas de extinção (MMA 2008). Caracteriza-se por apresentar as folhas subverticiladas em direção ao ápice dos râmulos.

10. Ocotea porosa (Nees) Barroso, Rodriguésia 24: 140. $1949 . \quad$ Fig. 1 (e1-e5)

Árvore monóica, até $8 \mathrm{~m}$ alt. Folhas alternas, peninervadas, raro sub-3-plinervadas, lâmina 4$8 \times 2-3,5 \mathrm{~cm}$, elíptica, ápice acuminado ou caudado, base aguda, glabrescente, reticulação densa, conspícua, face adaxial com nervura 
central subsaliente, nervuras laterais planas, buladas sobre as domácias, face abaxial com nervura central saliente, nervuras laterais planas, 4-7 pares, ângulo de divergência das nervuras $40^{\circ}$, domácias nas axilas das nervuras laterais até a metade da lâmina, cobertas por tricomas amarelo-ferrugíneos, pecíolo ca. $8 \mathrm{~mm}$ compr., canaliculado, glabro. Inflorescência ca. $3 \mathrm{~cm}$ compr., no ápice dos ramos e axilar, racemosa, pauciflora, pubérula. Flores bissexuadas, ca. 3 mm diâm., glabrescentes, tépalas ca. 2,2 mm compr., subiguais, elípticas, anteras 4esporangiadas, esporângios dispostos em 2 pares sobrepostos, estames das séries I e II ca. 1,2 mm compr., anteras ovalado-quadrangulares, filetes com igual comprimento que as anteras, glabros, estames da série III ca. 1,6 mm compr., anteras retangulares, filetes glabrescentes, estaminódios subsagitados no ápice, pubérulos, pistilo ca. 2,1 mm compr., glabro, ovário elipsóide, estilete longo. Fruto ca. $12 \times 11 \mathrm{~mm}$, globoso, cúpula ca. $9 \times 9 \mathrm{~mm}$, subemisférica a quase plana, margem inteira.

Material examinado: BRASIL. PARANÁ: Guaratuba, Serra de Araçatuba, 31.I.1960, fl., G. Hatschbach 6683 (MBM); 27.VIII.1999, fr., E.P. Santos et al. 796 (UPCB); 24.IX.1999, fr., E.P. Santos \& C. Blum 811 (UPCB); 14.I.2000, fl., E.P. Santos et al. 867 (UPCB); 24.X.2001, fr., E.P. Santos \& L.G. Socher 1068 e 1072 (UPCB); 22.IX.2006, fr., M.L. Brotto 3 (SPSF, UPCB); 25.I.2007, fl., M.L. Brotto et al. 9 (UPCB); 30.III.2007, fl., M.L. Brotto \& E.P. Santos 16 (UPCB).

Ocorre em São Paulo e na Região Sul do Brasil, na FOM e FOD. No Morro dos Perdidos é freqüente no patamar Altomontano a partir de 1200 m s.n.m. Acompanha esta formação por toda a cimeira das montanhas da Serra do Mar no Paraná. Espécie incluída na lista oficial das espécies da flora brasileira ameaçadas de extinção (MMA 2008). Assemelha-se a $O$. elegans diferindo pela forma do fruto e da cúpula e na folha pelo ângulo de divergência das nervuras. Floresce de janeiro a março e frutifica de agosto a outubro.

Ocotea porosa é confundida com $O$. catharinensis porém a forma do fruto e da cúpula as diferenciam. Em O. porosa, o fruto é globoso e a cúpula subemisférica a quase plana, enquanto que em $O$. catharinensis o fruto é elíptico e a cúpula hemisférica.

11. Ocotea pulchella (Meisn.) Mez, Jahrb. Königl. Bot. Gart. Berlin 5: 317. 1889.

Fig. 1 (f1-f5)

Árvore dióica, até $5 \mathrm{~m}$ alt. Folhas alternas, sub-3-plinervadas, lâmina 4-8 × 1,5-3,5 cm, lanceolada a elíptica, ápice agudo ou acuminado, base aguda, glabrescente, reticulação densa, conspícua, face adaxial com nervuras central e laterais planas, face abaxial com nervura central saliente, nervuras laterais subsalientes, 4-5 pares, domácias nas axilas das nervuras, cobertas por tricomas alvos, pecíolo 5-8 mm compr., subcanaliculado, glabrescente. Inflorescência ca. 6 cm compr., subterminal e axilar, racemosa, pauciflora, pubérula. Flores unissexuadas; estaminadas ca. $5 \mathrm{~mm}$ diâm., pubérulas, tépalas ca. $2 \mathrm{~mm}$, subiguais, ovaladas, anteras 4-esporangiadas, esporângios dispostos em 2 pares sobrepostos, estames das séries I e II ca. 1,4 mm compr., anteras ovalado-retangulares, filetes com igual comprimento que as anteras, glabrescentes, estames da série III ca. 1,5 mm compr., anteras retangulares, contraídas no meio, filetes glabrescentes, estaminódios estipiformes ou ausentes, pistilóide ca. $2 \mathrm{~mm}$, glabro; pistiladas ca. 4 mm diâm., pubérulas, tépalas ca. 1,8 mm compr., subiguais, ovaladas, estaminódios ca. $1 \mathrm{~mm}$, pistilo ca. 2,3 mm compr., glabro, ovário globoso, estilete longo. Fruto ca. $10 \times 7 \mathrm{~mm}$, elipsóide, cúpula ca. $6 \times 6 \mathrm{~mm}$, subemisférica, margem inteira.

Material examinado: BRASIL. PARANÁ: Guaratuba, Serra de Araçatuba, 05.V.2000, fr., E.P. Santos et al. 905 (SPSF, UPCB); 30.III.2001, fl. ¿े," E.P. Santos et al. 873 (SPSF, UPCB); 17.VIII.2001, fr., E.P. Santos et al. 1028 (SPSF, UPCB); 24.X.2001, fr., E.P. Santos \& L.G. Socher 1070 (SPSF, UPCB); Piraquara, Mananciais da Serra, II.2006, fl. $\delta^{\Uparrow}, M$. Reginato 671 (UPCB).

Ocorre nas Regiões Centro-Oeste, Sudeste e Sul do Brasil, na FES, FOM, FOD e no Cerrado. No Morro dos Perdidos é encontrada no patamar Montano e Altomontano entre 850- 
1320 m s.n.m, sendo a única para as duas formações. Assemelha-se a $O$. bicolor e $O$. tristis. Difere pela cúpula do fruto trompetiforme de margem hexalobada em $O$. bicolor e subemisférica em $O$. pulchella, fruto globoso em $O$. tristis e elíptico em $O$. pulchella. Coletada com flores em março e com frutos em maio, agosto e outubro.

12. Ocotea tristis (Nees) Mez, Jahrb. Königl. Bot. Gart. Berlin 5: 316. 1889.

Fig. 1 (g1-g6)

Árvore dióica, até $6 \mathrm{~m}$ alt. Folhas alternas, peninervadas, lâmina $2,5-6 \times 1,5-3 \mathrm{~cm}$, elíptica, ápice agudo, base aguda, face adaxial glabra, reticulação laxa, conspícua, nervuras central e laterais planas, face abaxial glabrescente, reticulação densa, conspícua, nervura central saliente, nervuras laterais planas, 4-6 pares, domácias nas axilas das nervuras, cobertas por tricomas alvos, pecíolo $7 \mathrm{~mm}$ compr., canaliculado, glabro. Inflorescência ca. $3 \mathrm{~cm}$, subterminal, racemosa, pauciflora, pubérula. Flores unissexuadas; estaminadas ca. $5 \mathrm{~mm}$ diâm., pubérulas, tépalas ca. 2,2 $\mathrm{mm}$ compr., subiguais, elípticas, anteras 4-esporangiadas, esporângios dispostos em 2 pares sobrepostos, estames das séries I e II ca. 1,4 mm compr., anteras ovaladoretangulares, filetes glabros, estames da série III ca. $1,8 \mathrm{~mm}$ compr., anteras retangulares, filetes com igual comprimento que as anteras, glabros, estaminódios ausentes, pistilóide ca. 2,4 mm compr., glabro; pistiladas ca. 3 mm diâm., pubérulas, tépalas ca. 1,9 $\mathrm{mm}$ compr., subiguais, elípticas, estaminódios ca. $1 \mathrm{~mm}$ compr., pistilo ca. $2 \mathrm{~mm}$ compr., glabro, ovário globoso, estilete curto. Fruto ca. $7 \times 6 \mathrm{~mm}$, globoso, cúpula ca. 4 $\times 4 \mathrm{~mm}$, subemisférica, rasa, margem inteira.

Material examinado: BRASIL. PARANÁ: Guaratuba, Serra de Araçatuba, 10.III.1959, fl., G. Hatschbach 5554 (MBM); 21.I.1994, fl., $R$. Kummrow et al. 3384 (MBM); 15.XI.1995, fr., J.M. Silva et al. 1512 (MBM); 22.I.1999, fr., E.P. Santos et al. 732 (UPCB); 05.III.1999, fl. Oे, , E.P. Santos et al. 760 (UPCB); 30.III.2007, fl. OA,, M.L. Brotto \& E.P. Santos 17(SPSF, UPCB); 30.III.2007, fl. @, M.L. Brotto \& E.P. Santos 18 (SPSF, UPCB); 05.VII.2007, fl. Oै, ,M.L. Brotto et al. 28 (UPCB).
Ocorre nas Regiões Sudeste e Sul do Brasil, na FOM, FOD e no Cerrado, inclusive em ambiente campestre. No Morro dos Perdidos é freqüente no patamar Altomontano a partir de 1200 m s.n.m. Acompanha esta formação por toda a cimeira das montanhas da Serra do Mar no Paraná. Assemelha-se a $O$. pulchella da qual difere pela forma do fruto, reticulação e nervação da folha. Espécimes coletados no segundo planalto do estado do Paraná apresentam folhas alternas muito próximas entre si, de forma elíptica ou orbicular e ápice obtuso-arredondado, enquanto que as encontradas na Serra do Mar apresentam folhas mais distanciadas entre si, estreitas e de ápice agudo. Coletada com flores de janeiro a março e julho e com frutos em novembro e janeiro.

13. Ocotea vaccinioides (Meisn.) Mez, Jahrb. Königl. Bot. Gart. Berlin 5: 252. 1889.

Fig. 1 (h1-h4)

Árvore monóica ou ginodióica, até $15 \mathrm{~m}$ alt. Folhas alternas, peninervadas, lâmina 3-9 $\times 1-2 \mathrm{~cm}$, lanceolada, ápice acuminado, base acuminada, reticulação laxa, inconspícua, face adaxial glabrescente, nervuras central e laterais planas, face abaxial pubérula, nervura central saliente e laterais planas, 6-8 pares, domácias distribuídas por toda a lâmina, não cobertas por tricomas, pecíolo $4-8 \mathrm{~mm}$ compr., não canaliculado, pubérulo. Inflorescência ca. $5 \mathrm{~cm}$ compr., subterminal e axilar, paniculada, pauciflora, tomentosa. Flores bissexuadas, ca. $3 \mathrm{~mm}$ diâm., tomentosas, tépalas ca. 2,4 mm compr., iguais, elípticas, anteras 4esporangiadas, esporângios dispostos em 2 pares sobrepostos, estames das séries I e II ca. 1,2 mm compr., anteras ovaladoquadrangulares, filetes $\operatorname{com} 1 / 3$ do comprimento das anteras, glabros, estames da série III ca. $1,5 \mathrm{~mm}$ compr., anteras retangulares, filetes glabrescentes, estaminódios ausentes, pistilo ca. 1,8 mm compr., glabro, ovário elíptico, estilete longo; pistiladas ca. $3 \mathrm{~mm}$ diâm., tomentosas, tépalas ca. 1,2 mm compr., iguais, ovaladas, estaminódios ca. 0,8 mm compr., papilosos, pistilo ca. $1,4 \mathrm{~mm}$ compr., glabro, 
ovário globoso, estilete curto. Fruto ca. $17 \times$ $12 \mathrm{~mm}$, elíptico, cúpula ca. $12 \times 9 \mathrm{~mm}$, trompetiforme, margem inteira.

Material examinado: BRASIL. PARANÁ: Guaratuba, Serra de Araçatuba, 18.XII.2001, fl., E.P. Santos et al. 1104 (SPSF, UPCB); 31.X.2006, fr., M.L. Brotto \& M.M.F. Zanon 5 (SPSF, UPCB); Morretes, Serra do Marumbi, Pico Olimpo, 10.I.1996, fl., O.S. Ribas et al. 937 (MBM); Quatro Barras, Morro Sete, 31.I.1989, fl. 9, J.M. Silva et al. 615 (MBM); Serra da Baitaca, Anhangava, 15.XII.1994, fl.ô, C.V. Roderjan 1139 (EFC).

Ocorre nas Regiões Sudeste e Sul do Brasil, na FOD. No Morro dos Perdidos é encontrada no patamar Montano a 850 m s.n.m. Difere das demais espécies de Ocotea principalmente por apresentar domácias por toda a lâmina das folhas. Em material vivo a cúpula do fruto é avermelhada. Coletada com flores de dezembro a janeiro e com frutos em outubro.

Ocotea vaccinioides pode ser confundida com O. daphnifolia (Meissn.) Mez, entretanto esta caracteriza-se por apresentar a folha com face abaxial enrugada, o que não ocorre em O. vaccinioides.

\section{Ocotea sp.}

Fig. 1 (i1-i5)

Árvore dióica, até $14 \mathrm{~m}$ alt. Folhas alternas, peninervadas, lâmina $4-8 \times 1-2 \mathrm{~cm}$, lanceolada, ápice acuminado, base aguda, face adaxial glabra, reticulação densa, inconspícua, nervura central plana a imersa, nervuras laterais planas, face abaxial glabra, reticulação densa, conspícua, nervuras central e laterais salientes, 4-6 pares, domácias ausentes, pecíolo 4-10 $\mathrm{mm}$ compr., subcanaliculado, viloso. Inflorescência ca. $4 \mathrm{~cm}$ compr., subterminal e axilar, racemosa ou paniculada, pauciflora a multiflora, vilosa. Flores unissexuadas; estaminadas ca. 4 mm diâm., vilosas, tépalas ca. 2,1 mm compr., subiguais, elípticas, anteras 4-esporangiadas, esporângios dispostos em 2 pares sobrepostos, estames das séries I e II ca. 2,3 mm compr., anteras ovaladoretangulares, filetes com igual comprimento que anteras, pubérulos, estames da série III ca. 2,3 $\mathrm{mm}$ compr., anteras ovalado-retangulares, filetes pubérulos, estaminódios filiformes, pubérulos, pistilóide ca. 2,8 mm compr., velutino; pistiladas ca. $6 \mathrm{~mm}$ diâm., vilosas, tépalas ca. $4 \mathrm{~mm}$, iguais, ovalado-triangulares, estaminódios das séries I e II ca. 1,5 mm compr., filetes pubérulos, estaminódios da série III ca. 1,3 mm compr., filetes pubérulos, estaminódios subsagitados no ápice, pistilo ca. 3,5 mm compr., ovário globoso, estilete longo, velutino. Fruto ca. $15 \times 15 \mathrm{~mm}$, globoso, cúpula ca. $7 \times 5 \mathrm{~mm}$, subemisférica, rasa, margem inteira.

Material examinado: BRASIL. PARANÁ: Guaratuba, Serra de Araçatuba, 07.V.2007, fl. , E.P. Santos \& M.L. Brotto 1184 (SPSF, UPCB); 05.VII.2007, fr., M.L. Brotto et al. 33 (UPCB); 25.IX.2007, fr., M.L. Brotto et al. 39 (UPCB). Tijucas do Sul, 27.III.1990, fl. ̊ै, J.M. Silva \& G. Hatschbach 838 (MBM); Tunas do Paraná, 23.III.2001, fl., J.M. Silva et al. 3357 (MBM).

No Morro dos Perdidos é encontrada na FOD Montana a $950 \mathrm{~m}$ s.n.m. As coletas de Silva \& Hatschbach 838 e Silva et al. 3357 estavam equivocadamente determinadas no herbário MBM como O. lancifolia (Schott) Mez. Assemelha-se, vegetativamente, a Ocotea pulchella (Meisn.) Mez, mas nesta o pecíolo é mais curto e robusto, as domácias são presentes e conspícuas e as nervuras laterais mais salientes. No Morro dos Perdidos é a única Ocotea com inflorescência e flores vilosas. Coletada com flores em maio e com frutos de julho a setembro.

\section{Persea willdenovii Kosterm., Reinwardtia} 7: 511. 1969.

Fig. 2 (f1-f5)

Árvore monóica, até $8,5 \mathrm{~m}$ alt. Folhas alternas, peninervadas, lâmina 9-17 × 3,5-7 $\mathrm{cm}$, obovada, ápice obtuso ou arredondado, base um pouco assimétrica, aguda ou obtusa, reticulação densa, conspícua, face adaxial glabra, nervura central plana a imersa, nervuras laterais planas, face abaxial glabrescente, nervuras central e laterais salientes, 7-9 pares, domácias ausentes, pecíolo 14-26 mm compr., canaliculado, glabrescente. Inflorescência ca. $7 \mathrm{~cm}$ compr., subterminal, paniculada, multiflora, tomentosa. Flores bissexuadas, ca. $5 \mathrm{~mm}$ diâm., pubescentes, tépalas fortemente desiguais, as externas ca. 1,8 $\mathrm{mm}$ compr., 
ovaladas, as internas ca. $5 \mathrm{~mm}$ compr., estreitoelipticas, anteras 4-esporangiadas, esporângios dispostos em 2 pares sobrepostos, estames das séries I e II ca. 3 mm compr., anteras ovaladas, filetes com o dobro do comprimento das anteras, velutinos, estames da série III ca. 3,8 mm compr., anteras ovaladas, filetes velutinos, estaminódios sagitados, velutinos, pistilo ca. 3,4 mm compr., glabro, ovário globoso, estilete longo. Fruto ca. $12 \times 12 \mathrm{~mm}$, globoso, assentado sobre pedicelo obcônico, $5 \times 4 \mathrm{~mm}$, levemente engrossado, segmentos das tépalas persistentes.

Material examinado: BRASIL. PARANÁ: Campina Grande do Sul, Serra do Ibitiraquire, 17.VIII.1996, fr., O.S. Ribas et al. 1476 (MBM); Guaratuba, Serra de Araçatuba, 05.VII.2007, est., M.L. Brotto et al. 27 (UPCB); Quatro Barras, Morro Anhangava, 15.XII.1993, fl., C.V. Roderjan 1117 (MBM, UPCB); Jaguariaíva, 05.XII.1988, fl., C. Muller et al. s.n. (MBM 283048).

Ocorre nas Regiões Centro-Oeste, Sudeste e Sul do Brasil, na FES, FOM, FOD e no Cerrado. No Morro dos Perdidos é encontrada no patamar Altomontano a partir de $1200 \mathrm{~m}$ s.n.m. Entre as Lauraceae que ocorrem no Morro dos Perdidos é a única com tépalas fortemente desiguais e folhas com ápice obtuso ou arredondado. É frequentemente referida nos herbários como Persea pyrifolia Nees, mas este é um homônimo posterior de Persea pyrifolia (D. Don) Spreng., o que levou Kostermans (1969) a publicar o novo nome (Baitello \& Moraes 2005).

\section{REFERÊNCIAS BIBLIOGRÁFICAS}

Baitello, J. B. (coord.) 2003. Lauraceae. In: Wanderley, M. G. L.; Shepherd, G.; Giulietti, A. M. \& Melhem, T. M. (eds.). Flora fanerogâmica do estado de São Paulo. FAPESP/RiMa, São Paulo, 3:149-223.

Baitello, J. B. \& Moraes, P. L. R. 2005. Lauraceae. Flora Fanerogâmica da Ilha do Cardoso, São Paulo 11: 31-70.

Blum, C. T. 2006. A Floresta Ombrófila Densa na Serra da Prata, Parque Nacional SaintHilaire/Lange, PR - caracterização florística, fitossociológica e ambiental de um gradiente altitudinal. Dissertação de Mestrado. Universidade Federal do Paraná, Curitiba, 185p.

Brotto, M. L.; Vieira, T. \& Santos, E. P. 2007. Flórula do Morro dos Perdidos, Serra de Araçatuba, Paraná, Brasil: Aquifoliaceae. Estudos de Biologia 29(67): 129-135.

Brummit, R. K. \& Powell, C. E. 1992. Authors of plant names. Kew Gardens, Surrey, 732p.

Cervi, A. C. \& Santos, E. P. 2000. Flórula do Morro dos Perdidos, Serra de Araçatuba, Estado do Paraná, Brasil: Passifloraceae. Estudos de Biologia 22(46): 25-47.

Gentry, A. 1988. Changes in plant community diversity and floristic composition on environmental and geographical gradients. Annals of the Missouri Botanical Garden 69: 557-593.

Hefler, S. M.; Cervi, A. C.; Santos, E. P. 2003. Flórula do Morro dos Perdidos, Serra de Araçatuba, estado do Paraná, Brasil: Plantaginaceae. Estudos de Biologia 25(50): 17-21.

Holmgren, P.K. \& Holmgren, N.H. 1998 [continuamente atualizado]. Index Herbariorum: A global directory of public herbaria and associated staff. New York Botanical Garden's Virtual Herbarium. http://sweetgum.NY.org/ih/

Inoue, M. T.; Roderjan, C. V. \& Kuniyoshi, Y. S. 1984. Projeto madeira do Paraná. Fundação de Pesquisas Florestais, Curitiba, 260p., il.

Klein, R. M.; Reis, A. \& Reitz, R. 1979. Madeiras do Brasil. Ed. Lunardelli, Florianópolis, 320p., il.

Kostermans, A. J. G. H. 1969. Revision of Lauraceae II. Reinwardtia 7: 511.

Lorenzi, H. \& Souza, V. C. 2008. Botânica sistemática: guia ilustrado para identificação das famílias de Fanerógamas nativas e exóticas no Brasil, baseado em APG II. Instituto Plantarum: Nova Odessa, São Paulo, 2 ed, p.85-89.

Marques, C. A. 2001. Importância econômica da família Lauraceae Lindl. Revista Floresta e Ambiente 8(1): 195-206. 
Ministério do Meio Ambiente (MMA). 2008. Instrução Normativa $\mathrm{N}^{\circ} 6$ de 23/09/2008.

Quinet, A. \& Andreata, R. H. P. 2002. Lauraceae Jussieu na Reserva Ecológica de Macaé de Cima, Município de Nova Friburgo, Rio de Janeiro, Brasil. Rodriguésia 53(82): 59-121.

Rocha, M. do R. L. 1999. Caracterização fitossociológica e pedológica de uma Floresta Ombrófila Densa Altomontana no Parque Estadual Pico do Marumbi - Morretes, PR. Dissertação de Mestrado. Universidade Federal do Paraná, Curitiba, 81p.

Roderjan, C. V.; Galvão, F.; Kuniyoshi, Y. S. \& Santos, E. P. 2001. Caractérisation des unités phytogéographiques dans l'Etat du Paraná, Brésil, et leur état de conservation. Biogeographica 77(4): 129-140.

Rohwer, J. G. 1986. Prodromus einer Monographie der Gattung Ocotea Aubl. (Lauraceae), sensu lato. Mitteilungen aus dem Institut fur Allgemeine botanik Hamburg 20:1-278.

Salvador, G. S.; Santos, E. P. \& Cervi, A. C. 2005. Flórula do Morro dos Perdidos, Serra de Araçatuba, Estado do Paraná, Brasil: Ochnaceae. Estudos de Biologia 27(61): 13-17.

Silva, R. S.; Cervi, A. C. \& Santos, E. P. 2007. Flórula do Morro dos Perdidos, Serra de Araçatuba, Paraná, Brasil: Ericaceae. Estudos de Biologia 29: no prelo.

Slusarski, S. R.; Cervi, A. C.; Guimarães, A. O. \& Santos, E. P. 2003. Flórula do Morro dos Perdidos, Serra de Araçatuba,
Estado do Paraná, Brasil: Clusiaceae, gênero Hypericum L. Estudos de Biologia 25(50): 23-28.

Vattimo, I de. 1956a. O gênero Ocotea Aubl. no Sul do Brasil. I. Espécies de Santa Catarina e Paraná. Rodriguésia 18/19(30/ 31): 265-350.

Vattimo, I de. 1956b. Nota prévia sobre as espécies de Ocotea Aubl. que ocorrem no Estado do Paraná. Arquivos do Serviço Florestal 10: 109-123.

Vattimo, I de. 1962. O gênero Ocotea Aubl. nos estados de São Paulo e Rio Grande do Sul. Apêndice: notas sobre o gênero Cinnamomum Boehm, no Brasil. Arquivos do Jardim Botânico do Rio de Janeiro 17: 199-226.

Vattimo, I de. 1979. Contribuição ao conhecimento da distribuição geográfica das Lauráceas V. Novas localidades nos Estados do Paraná e Rio Grande do Sul. Rodriguésia 31(50): 135-152.

Vieira, E. R.; Santos, E. P. \& Tardivo, R. C. 2003. Flórula do Morro dos Perdidos, Serra de Araçatuba, estado do Paraná, Brasil: Iridaceae. Estudos de Biologia 25(51): 17-29.

Werff, H. van der. 1991. A key to the genera of Lauraceae in the new world. Annals of the Missouri Botanical Garden 78: 377-387.

Werff, H. van der. \& Ritcher, H. G. 1996. Toward and improved classification of Lauraceae. Annals of the Missouri Botanical Garden 83: 409-418. 